\title{
Vergi Harcamalarının Ekonomik Açıdan Değerlendirilmesi: Türkiye Örneği
}

\author{
Nihat Doğanalp ${ }^{1 *}$ \\ ${ }^{1}$ Selçuk Üniversitesi, Beyşehir Ali Akkanat İşletme Fakültesi, İşletme Bölümü, Konya, Türkiye (ORCID: 0000-0003-4934-179X)
}

(İlk Geliş Tarihi 23 Ocak 2020 ve Kabul Tarihi 22 Şubat 2020)

(DOI: 10.31590/ejosat.679111)

ATIF/REFERENCE: Doğanalp, N. (2020). Vergi Harcamalarının Ekonomik Açıdan Değerlendirilmesi: Türkiye Örneği. Avrupa Bilim ve Teknoloji Dergisi, (18), 201-205.

$\ddot{\mathbf{O z}}$

Devletlerin en önemli ve sağlıklı finansman kaynağı topladıkları vergilerdir. Ancak bazı durumlarda devletler ekonomik, sosyal, kültürel vb. sebeplerle bu önemli gelir kaynağından vazgeçebilirler. Vergi harcamaları devletin gelir kaybına yol açan yöntem olarak kamu harcamalarına yakınsayan bir uygulama olarak göze çarpmaktadır. Ancak bütçe disiplini ekseninde düşünüldüğünde hükümetlerin vergi harcamasının mali açıdan getirdiği yükü ve bu harcamalarla birlikte ortaya çıkacak faydayı etkin bir şekilde analiz etmeleri gerekmektedir. Bundan dolayı tüm ekonomilerde vergi harcamalarının sağlıklı ve sıkı bir disiplin ile takip edilmesi gerekmektedir.

1960'tan bu yana önem kazanmaya başlayan bir kavram olan vergi harcaması Türkiye'de 2000'den bu yana gündem oluşturmaya başlamış ve Maliye Bakanlığı bünyesinde ilk vergi harcaması raporu 2001 yılında yayımlanarak 10/12/2003 tarihli ve 5018 sayılı Kamu Mali Yönetimi ve Kontrol Kanunu’nda vergi harcaması ile ilgili mevzuata yer verilmiştir.

Anahtar Kelimeler: Vergi Harcaması, Türk Vergi Sistemi, Vergi Teşvikleri

\section{Economic Aspects of Tax Expenditures: Case of Turkey}

\begin{abstract}
The most important and sound source of financing by the states is the taxes they collect. However, in some cases, states may be economical, social, cultural, etc. For these reasons, they can give up this important source of income. Tax expenditures stand out as an application converging to public expenditures as the method leading to the loss of income of the state. However, when the budget is considered in the axis of the discipline, governments must effectively analyze the financial burden of tax expenditure and the benefit that will occur with these expenditures. Therefore, in all economies, tax expenditures should be followed with a healthy and strict discipline.

1960 expenditure tax, a concept began to gain importance since from 2000, Turkey has started to create the agenda since the first tax expenditure report of the Ministry of Finance published in 2001 dated 10.12.2003 and the 5018 Public Financial Management and Control Law The legislation on tax expenditure has been included in.
\end{abstract}

Keywords: Tax Expenditure, Turkish Tax System, Tax Incentives

\footnotetext{
* Sorumlu Yazar: Selçuk Üniversitesi, Beyşehir Ali Akkanat İşletme Fakültesi, Beyşehir-Konya, Türkiye, ORCID: 0000-0003-4934-179X, ndoganalp@selcuk.edu.tr
} 


\section{Giriş}

Bazı ülkelerin tüm mali faaliyetlerine yönelik harcamalar kasıtlı olarak veya yanlışlıkla gizlenmedikleri sürece kayıt altına alınabilir ve bu tür harcamalar kamu harcamaları olarak gösterilmez. Kelimenin en geniş anlamıyla bu tür faaliyetler vergi harcamaları veya harcama vergisi başlığı altında değerlendirilirler. Bu faaliyetler; vergi istisnaları, muafiyetler, vergi matrahının veya ödenmesi gereken verginin azaltılması gibi pek çok formda uygulanabilirler.

Vergi harcamaları, hükümetlerin belirli mükellef gruplarını (kategori, sektör, firma veya birey) desteklemek ve verilen ekonomik faaliyetlere teşvik sağlamak amacıyla kullandığı bir araçtır. Böyle bir durumda, hükümet bilinçli olarak kendi gelirinin azaltılması konusunda hemfikirdir. Hükümetin vergileri tüm üslerden toplaması ve daha sonra bütçenin harcama tarafından doğrudan hibeler veya yardım tahsis etmesi durumunda da aynı etki sağlanacaktır. Ana ayrım, bu tarzın kıyaslanamaz şekilde daha şeffaf olacağıdır.

Vergi harcamaları, nitelikli bireylere/kuruluşlara fayda sağlayarak veya belirli faaliyetleri teşvik ederek hedeflenen kamu politikası hedeflerine ulaşmayı amaçlamaktadır. Ayrıca, vergi eşitliğinin geliştirilmesi veya vergi yapısının diğer bölümlerindeki kusurların dengelenmesi de amaçlanabilir. Aynı hedeflere (örneğin ailelere mali yardım) doğrudan harcama veya vergi muafiyeti yoluyla da ulaşılabilir.

Belirli bir vergi önleminin vergi harcaması oluşturup oluşturmadığını belirlemek için, öncelikle bu önlemin bir ayrımı temsil ettiği normal vergi yapısının oluşturulması gerekir. Literatürde bazı vergi harcamalarının vergi mükelleflerinin davranışlarında meydana gelen değişiklikleri dikkate alarak, vergi harcamalarının etkisini değerlendirmek için hükümetlerin başvurduğu bir yöntem olduğunu savunan görüşler de yer almaktadır (Bratic, 2006: 114).

Ancak vergi harcamalarının da olumsuz özellikleri vardır, her şeyden önce vergi harcamalarıyla birlikte vergi sisteminin tarafsızlık ilkesi bozulmaktadır. Tarafsız bir vergi sistemi, herhangi bir vergi harcaması olmaksızın ve standart bir vergilendirme sistemi ile geniş bir vergi matrahını üstlenir. Vergi harcamalarının başka birçok olumsuz yönü vardır. Vergi idaresinin maliyetlerini arttırırlar ve vergi sisteminin ve kamu finans sisteminin bir bütün olarak şeffaflığını azaltırlar çünkü genellikle diğer harcama türleriyle aynı iç kontrol ve yasal yetkilendirme sistemine tabi değildirler; genellikle merkezi hükümet gelirlerinin azaltılması üzerinde doğrudan etkisi olan maliyetler ve faydalar hakkında tam bir anlayış ve analiz yapılmadan tanıtılır ve genellikle vergilendirme ilkelerinin bazılarını (eşitlik, eşitlik, üretkenlik, etkililik, istikrar ve etkililik ilkesi) bozarlar (Polackova vd., 2004: 11).

Weinberg (1987) vergi harcamalarını bazı vergi hükümlerinin, mükelleflerin belli davranışlarını teşvik etmek için veya belli bir çerçevede mükellefleri desteklemek üzere düzenlendiği, vergi kanunlarındaki bu tür vergi hükümlerinin, geleneksel bütçe harcamalarını andırdığı ve bu nedenle vergi harcamaları diye adlandırıldıkları ifade edilmiştir. Her ülkenin vergi sistemi kendine özgü bazı özellikler taşımaktadır. Her ne kadar bütün vergi sistemlerinin kurulmasında göz önünde tutulan bazı ortak amaçlar mevcut olsa da, ülkelerde vergileme ile ulaşılmak istenen amaçlar iktisadi seviye, tarihsel, sosyolojik ve siyasal yapıya göre farklılık göstermektedir (Nadaroğlu, 1985: 450). Vergi harcaması, devletin vergi gelirlerinin bir kısmından vazgeçmesi ile kendini gösteren vergisel düzenlemeler ve bu düzenlemelerin kamu gelirlerinde yarattığı kayıptır (Gülmez, 2003: 6). Vergi istisna ve muafiyet uygulamalarından doğacak vergi yükünün nasıl dağılacağı, ne tür iktisadi faaliyetlerin destekleneceği ve bu uygulamanın kamu gelirleri açısından nasıl bir kayba yol açacağı ekonomistlerin hemen hemen her dönemde ilgi duydukları bir konu olmuştur (Pedük, 2006: 17).

\section{Vergi Harcaması Kavramı}

Devletin faaliyetlerini yürütürken belirli amaçlar doğrultusunda vazgeçtiği bir gelir olan vergi harcamaları, vergi sistemlerinde istisna, muafiyet, vergi ertelemesi, düşük vergi oranı gibi yöntemlerle uygulanmaktadır. Vergi harcaması kavramının temeli ABD’de 1950'li ve 1960'll yıllarda federal gelir vergisinde ve kurumlar vergisindeki istisna ve muafiyetlerin, vergi mahsuplarının (tax credits), vergi indirimlerinin (tax deductions) ve oran indirimlerinin (rate reliefs) esas itibariyle federal bütçe harcamalarından farklı bir şey olmadığı görüşüne dayanmaktadır (Bittker, 1969: 244).

Vergi kavramına ilişkin çok sayıda farklı tanımlama yapılmış olmasına karşın literatürde en yaygın kabul görmüş tanımlama devletin birey veya tüzel kişiliğe sahip birimlerden konulan yasanın niteliği gereği cebren alınan ve bir karşılığın vaat edilmediği iktisadi değerdir (Nadaraoğlu, 2000: 193). Modern maliye anlayışı ve sosyal devlet anlayışının gelişmesiyle birlikte devletlerin belirli hedeflere ulaşmak için klasik kamu harcamalarından farklı olarak vergi harcamalarına başvurdukları görülmektedir. Vergi harcamaların her ne kadar 2000'li yıllardan sonra Türkiye'de önem kazanmaya başladığı söylense de yasal arka planının 1982 Anayasasının 2. maddesinde ifade edilen sosyal devlet ilkesi ile birlikte ortaya konmaya çalışıldığı söylenebilir.

Devletin kamusal faaliyet alanındaki en temel finansman kaynağı olan vergi uygulamalarıyla birlikte özel kesimden toplanan vergiler kamu harcaması vasıtasıyla yeniden özel kesime aktarılmaktadır. Vergi toplanması sürecinde devletin karşılaştığı iki tür maliyet söz konusudur. Bunlardan ilki vergi toplamanın doğurduğu idari maliyetler, ikincisi ise devletin kendi iradesiyle vazgeçtiği vergi gelirleri olarak değerlendirilen vergi harcamalarının doğurduğu maliyetlerdir (Ferhatoğlu, 2005: 78).

ABD'de 1974 yılında yürürlüğe giren Bütçe Reform Yasası'nda vergi harcamalarının kamu harcamaları gibi bir formda uygulandığı ve bundan dolayı diğer kamu harcamaları gibi bütçe denetimine tabi tutulması gerektiği ifade edilmiştir (Pedük, 2005: 15).

Denk bütçe yaklaşımı çerçevesinde ABD'de ilk kez Stanley Surrey’in önerileri doğrultusunda ABD Hazine Bakanı Fowder tarafından hazırlanan ve 1968 yılında yayımlanan Vergi Harcama Bütçesi: Kavramsal Bir Analiz raporunda vergi harcamalarına ilişkin denk bütçe yaklaşımına vurgu yapılmıştır (Öztürk, 2011: 5). 1969'da ise uygulama esasları bakımından klasik kamu harcamalarından farklılıklar arz eden vergi harcamalarına ilişkin bütçe kamuoyuyla paylaşılmıştır

Vergi harcamalarına ilişkin devletlerin ayrı bir bütçe planlaması yapmalarında fayda vardır çünkü anayasa dışında vergi harcamalarına olanak tanıyan diğer mevzuat ve yönetmeliklerde vergi harcamaları doğrudan bütçede değil vergilerin toplanmasından 
vazgeçilmek suretiyle yapılmış bir harcama kalemi olarak görülmekte ve bu da bütçedeki yükünü tespit etme noktasında belirsizliklere yol açmaktadır (Hepaksaz ve Çamurdan, 2010: 40).

Faydalarının yanısıra birçok olumsuz özelliği bulunan vergi harcamaları genelde karmaşık bir yapıya sahip olduğundan istenen sonuçlar her zaman planlandığı gibi gerçekleşmeyebilir. Ayrıca vergi harcamaları bir kere kanunlaştıktan sonra çıkar gruplarının baskılarıyla birlikte süreklilik kazanabilir. Sosyal yardım amacıyla kullanılan vergi harcamaları bile özellikle siyasi bağlantılara sahip kişiler tarafından istismar edilerek eş dost kayırmacılığı gibi etik dışı amaçlar için de kullanılabilir. Böylece kişisel çıkarlar için vergi kanunlarının esir alınması söz konusu olmaktadır (Horpedahl ve Pizzola, 2012:6-7).

\subsection{Vergi Harcamalarının Unsurları ve Sınıflandırılması}

Vergi harcamalarını kamu harcamalarından ayıran bazı özellikler vardır. Bu özellikler vergi harcamalarının unsurlarını oluşturmaktadır. Vergi harcamalarının varoluş nedeni, belli bir sosyal veya ekonomik nedenin olmasıyla bağlantılıdır. Ayrıca vergi harcamasının ortaya çıkması için bir tahsilattan vazgeçme söz konusu olmaktadır (Saraç, 2010: 264-265). Vergi harcamasından yararlandırılan mükellefler ödeyecekleri vergiden daha azını ödemektedir. Eğer yapılan bu indirim ve istisnalar tüm vergi mükelleflerine uygulanırsa, vergi harcaması ayrıcalıklı olmaktan çıkmaktadır. Örneğin Tarım ve Kırsal Kalkınmayı Destekleme Kurumu aracılığı ile belli bölgelere verilen teşvikler vergi harcaması kapsamında yer alabilir. Fakat bu teşvikler tüm ülkeye verilirse, burada vergi harcamasindan bahsedilemez.

Vergi harcamaları çerçevesinde tanınacak ayrıcalıkların belirli kesim veya mükellef üzerinde bir fayda sağlaması beklenir. Tanınacak vergi ayrıcalığının hesaplanabilir olması ve özel bir amaca hizmet etmesi de gerekmektedir. Diğer taraftan vergi harcamasının uygulanmasına ilişkin yasal zeminin hazır olması başka bir ifadeyle vergi harcamasının etkisini azaltacak bir engelin bulunmaması gerekmektedir. Tüm bunlar birlikte değerlendirildiğinde vergi harcaması uygulamalarının normatif bir uygulama olduğu göze çarpmaktadır (Özker, 2002: 47).

Vergi harcamaları sınıflandırılırken tek bir yöntem belirlenmiş olmayıp bu hususta vergi harcamalarının sınıflandırılması öznel nitelik taşımaktadır. Bununla birlikte yaygın olarak vergi harcamalarının uygulanacağı vergi matrahına, amaçlarına/hedeflerine veya ölçüm tiplerine göre sınıflandırma yapılmaktadır. Bu çerçevede ortaya çıkan vergi harcaması türleri:

- Muafiyetler ve istisnalar

- İndirimler

- Mahsuplar

- Vergi kredisi

- Düşük vergi oranı

- Vergi ertelemesi (vergi tatili) şeklinde sınıflandırılabilir.

\subsection{Vergi Harcamalarının Hesaplanması ve Raporlanması}

Vergi harcamalarının uygulanabilirliğindeki en önemli hususlardan birisi de bu harcamaların hesaplanabilir nitelikte olmasıdır. Verhi harcamalarını hesaplamada kullanılan üç yöntemden bahsetmek mümkündür. Bunlardan ilki ve en yaygın kullanılanı vazgeçilen gelir yöntemidir. Vergi harcamalarına ilişkin raporlama sürecinin sağlıklı bir şekilde yürütülebilesi için mutlaka ilgili harcamaların hesaplanması gerekmektedir. Bu sayede vergi harcamaların bütçedeki yükü ve ekonomik katkılarını mukayeseli olarak değerlendirmek mümkün olmaktadır. Vergi harcamalarına ilişkin raporlama sistemleri ülkeden ülkeye farklılıklar gösterse de her ülkede bu raporların temel amacı vergi ayrıcalıkları ve kamu harcamalarının karşılaştırmasını yapmaktır (Mcdonald, 2010: 20).

Vergi harcamalarının ölçüm ve tahmininde güvenirliliğinin geçerliliği ancak güvenilir verilerin elde edilmesiyle mümkün olabilmektedir. İlk ve en iyi kaynak olarak vergi mükelleflerinin hazırlamış oldukları vergi beyannameleri kabul edilir. Sonrasında ise ulusal hesaplar, nüfus anketleri, firma anketleri ticaret ve üretim istatistikleri vergi harcamalarının tahmininde kullanılabilecek diğer verilerdir. Bu veriler aynı zamanda karşılaştırmalı değerlendirme yapmayı da mümkün kılar. Vergi harcamalarının ölçülmesinde ve tahmininde üç farklı model kullanılır. Bu modeller toplama modeli, dağıtma modeli ve mikrosimilasyon modeli olarak sıralanabilir. Yine bu modeller kullanılırken verilerin yeterliliği ve güvenilirliği önemini korur (Swift, 2006: 22). Vergi harcamaları da doğrudan kamu harcamalarına benzerlik gösteren bir harcama olmasına rağmen miktarını belirleme ve bütçe sürecine dâhil etmeden kaynaklanan zorluklar nedeniyle oldukça detaylı bir analiz sürecini gerektirmektedir (Yılmaz, 2013: 17).

Vergi harcamalarından doğacak en önemli maliyet bu harcamalar sebebiyle devletin uğramış olduğu gelir kaybıdır. Vergi harcamasının temelinde devletin elde edeceği vergi gelirinin tahsilatından vazgeçilerek birey veya tüzel kişilere bırakılması yatmaktadır. Devlete gelir kaybı şeklinde bir maliyet doğuran bu harcamalar bazı durumlarda iktisadi olarak beklenen faydayı sağlamakta yetersiz kalabilirler (Ferhatoğlu, 2005: 82).

Bazı ülkelerde vergi harcamasına ilişkin raporlarını hazırlamak yasal bir zorunluluk iken bazı ülkelerde ise yasal zorunluluk olmasa da bu raporlar hazırlanabilmektedir. Pek çok ülkede yıllık olarak düzenlenen bu raporlar bazı durumlarda iki yılda bir bazen de ihtiyaç duyulduğunda hazırlanmaktadır (Pedük, 2006: 78-79).

Standart vergiden farklı olarak özel hükümlerin raporlanması bazen vergi harcaması bütçesi bazen de vergi harcaması raporları olarak tanımlanmaktadır. Bu raporlar, vergi kanunlarında yer alan harcama sisteminin bir özeti niteliğinde olup vergi harcamalarını değerlendirilme, teşvik etme ve vergi sistemini tasarlanma konusundaki bakış açısını da desteklemektedir (Coşkun, 2010: 56). 


\section{Türk Vergi Sistemi Ekseninde Vergi Harcamalarının Ekonomik Etkileri}

VIII. Beş Yıllık Kalkınma Planı hazırlık çalışmalarında, vergi harcamaları "Bütçe Kapsamı Dışında Kalan Dolaylı Kamusal Harcama Alanları" arasında değerlendirilmiş ve Türkiye'deki vergi harcamalarına ilişkin olarak bu harcamaların bütçelendirme sürecindeki sıkıntılara, vergi harcamalarının şeffaflı̆̆ı ve hesaplanabilirliğine ilişkin sorunlara vurgu yapılmıştır (Gönül, 2002: 71).

Türk vergi sisteminde yer alan vergi harcamalarının geneline bakıldığında bu harcamaların bazılarının üretimin, ihracatın ve sermaye birikimin artırılmasına yönelik olarak düzenlendiği görülmektedir. Sağllk, spor, eğitim ve kültürel faaliyetlerin geliştirilmesi, doğal afete maruz kalanları korumak gibi sosyal amaçlarla da bu harcamalar TVS içinde kendine yer bulmuştur. Bunların dışında diplomatik nitelikteki ve kamusal nitelikteki kurum/kuruluşlara tanınan ayrıcalıklar da bu kapsamda değerlendirilmektedir (Gülmez, 2003: 95). Vergi harcamalarının yatırım, tasarruf, üretim veya tüketimi teşvik eden amaçlarının yanı sıra ekonomik istikrarı sağlamaya ekseninde ödemeler dengesini iyileştirme, kapasite kullanımını arttırma, servet ve gelir dağılımını düzenlemeye yönelik amaçlarına da rastlanmaktadır (McDonald, 2010: 15).

Maliye politikası çerçevesinde uygulanan vergi politikaları ile korunmak ve geliştirilmek istenen alanlar için vergi teşviki, önlenmek istenen alanlar için vergileri ağırlaştırmak suretiyle bir uygulama olduğu bilinmektedir. Bu yönüyle vergi harcamalarının ekonomik büyüme hedefine yönelik temel araçlardan birisi olduğu, bu çerçevede hükümetlerin vergi ayrıcalığı sağlayarak desteklemek istediği kesim veya iş kollarındaki vergi yükünü hafifletmek veya hiç vergi almadan dolaylı olarak kaynak aktarımında bulunmak olduğu söylenebilir (Edizdoğan, 2007: 162).

2018 yılında yayımlanan vergi harcamaları raporunda 2017-2021 dönemine ilişkin ilgili vergi kanunları çerçevesinde gerçekleşebilecek vergi harcaması tahminlerine yer verilmiş̧ir. Bu tahminler Tablo 1'de sunulmuştur.

Tablo 1: 2017-2021 Dönemi Vergi Harcaması Tahminleri (Milyon TL)

\begin{tabular}{|l|l|l|l|l|l|}
\hline Kanun Adı & $\mathbf{2 0 1 7}$ & $\mathbf{2 0 1 8}$ & $\mathbf{2 0 1 9}$ & $\mathbf{2 0 2 0}$ & $\mathbf{2 0 2 1}$ \\
\hline Gelir Vergisi & 49.284 & 57.954 & 68.267 & 78.619 & 87.800 \\
\hline Kurumlar Vergisi & 19.567 & 23.560 & 28.031 & 32.435 & 36.159 \\
\hline Katma Değer Vergisi & 34.806 & 41.909 & 49.797 & 57.469 & 64.084 \\
\hline Özel Tüketim Vergisi & 17.619 & 21.215 & 24.903 & 27.970 & 31.190 \\
\hline Diğgr Kanunlar & 5.373 & 6.470 & 7.698 & 8.907 & 9.932 \\
\hline TOPLAM & 126.650 & 151.108 & 178.696 & 205.401 & 229.165 \\
\hline
\end{tabular}

Kaynak: Vergi Harcamaları Raporu, 2008: 284

Hükümetlerin vergi harcaması uygulamaları başta belli başlı sektörlerin gelişmesi ve nihai olarak ekonomik büyümeye katkı sağlaması amacıyla uygulansa da ilgili dönem GSYH'si içinde edindiği pay ile de hükümet açısından bir maliyet kalemi olarak da değerlendirilebilmektedir. $\mathrm{Bu}$ çerçevede 2017-2021 dönemine ilişkin vergi harcamalarının GSYH içindeki payları Tablo 2'de sunulmuştur.

Tablo 2: 2017-2021 Dönemi Vergi Harcaması Tahminlerinin GSYH’ye Oranı (\%)

\begin{tabular}{|l|l|l|l|l|l|}
\hline Kanun Adı & $\mathbf{2 0 1 7}$ & $\mathbf{2 0 1 8}$ & $\mathbf{2 0 1 9}$ & $\mathbf{2 0 2 0}$ & $\mathbf{2 0 2 1}$ \\
\hline Gelir Vergisi & 1,6 & 1,5 & 1,5 & 1,5 & 1,5 \\
\hline Kurumlar Vergisi & 0,6 & 0,6 & 0,6 & 0,6 & 0,6 \\
\hline Katma Değer Vergisi & 1,1 & 1,1 & 1,1 & 1,1 & 1,1 \\
\hline Özel Tüketim Vergisi & 0,6 & 0,6 & 0,6 & 0,5 & 0,5 \\
\hline Diğgr Kanunlar & 0,2 & 0,2 & 0,2 & 0,2 & 0,2 \\
\hline TOPLAM & 4,08 & 4,04 & 4,02 & 3,99 & 3,99 \\
\hline
\end{tabular}

Kaynak: Vergi Harcamaları Raporu, 2008: 284

\section{Sonuç ve Değerlendirme}

Vergi harcaması sadece kamu harcamalarının devlet bütçesi aracılığıyla değil aynı zamanda vergi sistemi aracılığıyla da yapılan bir uygulamadır. Türk Vergi Sistemi ekseninde değerlendirildiğinde bunun en açık göstergesi vergi harcamalarının -muafiyetler hariçdevlete getirdiği maliyet yüküdür. 1997-2001 dönemine ilişkin veriler incelendiğinde devletin elde ettiği her 1 TL'lik kurumlar vergisi gelirine karşılık 2,7 TL'lik kurumlar vergisi hasılatından vazgeçtiği görülmektedir. Sadece kurumlar vergisinde bu kadar maliyet doğuran uygulamanın diğer vergi türleri de dikkate alındığında devlete önemli bir maliyet yükü getirdiği aşikardır.

Vergi harcamasının sınıflandırılması ve tahminiyle ilgili zorluklara rağmen, vergi harcaması tahminlerinin yıllık raporlamas ekonomistler ve vergi hukuku gözlemcileri için önemli bir politika analizi kaynağıdır. Diğer taraftan bu maliyet yükünün ölçümüne ilişkin etkin bir sistem geliştirilemediği de söylenebilir. Bu da sistem içerisinde var olan vergi harcaması unsurlarının etkin olarak kullanılıp kullanılmadığı ve uluslararası karşılaştırmalar yapmada yetersiz enformasyona neden olmaktadır. 
Vergi harcamalarının etkileri ekseninde genel olarak bir değerlendirme yapılacak olursa barınma, sağlık hizmetleri ve tasarruf için temel vergi harcamaları, vergi sonrası gelirleri düşük gelirli vergi mükelleflerine göre daha yüksek gelirli vergi mükellefleri için daha fazla artırmaktadır, ancak en yüksek gelirli vergi mükellefleri gelirlerinin bir yüzdesi olarak tüm vergi mükelleflerinden nispeten daha az kazanmaktadır. Yüksek gelirli vergi mükelleflerinin vergi harcamalarından, düşük gelirli vergi mükelleflerine kıyasla daha fazla yararlandığı söylenebilir çünkü bu kesimlerin sübvansiyonlu faaliyetlere (örneğin ev sahipliği, işveren destekli sağlık sigortası ve emeklilik tasarruf planları) katılma olasılıkları daha fazladır. Ancak en yüksek gelir vergisi mükelleflerinin yararlanabilecekleri vergi harcaması miktarının da yasal olarak bir sınıra tabi olduğunu unutmamak gerekir.

Sonuç olarak ilgili birimler tarafından hazırlanacak olan vergi harcaması bütçesi ve analizleriyle, gerçekleștirilecek bir vergi reformunun vergi gelirleri ve ekonomi üzerindeki etkilerini ölçebilmek, reformun başarıya ulaşıp ulaşmadığını görebilmek ve kamu kesiminin büyüklüğ̈nn̈ kestirebilmek mümkün hale gelecektir. Bununla birlikte devlet bütçesine ilaveten vergi harcaması bütçesiyle TVS ekseninde uygulanan harcama tutarları tam olarak tespit edilerek etkinlik ve verimlilik denetimleriyle kamuoyu açısından şeffaf bir tablo ortaya çıkabilecektir.

\section{Kaynakça}

BITTKER, B. (1969). Accounting For Federal Tax Subsidies In The National Budget, National Tax Journal, 22(2), 244-261.

BRATIC, V. (2006). Tax Expenditures: A Theoretical Review, Financial Theory and Practice, 30(2), 113-127.

COŞKUN, Zeynep (2010), Tax Expenditures In The European Union and Turkey, Yayınlanmamış Yüksek Lisans Tezi, Orta Doğu Teknik Üniversitesi Sosyal Bilimler Enstitüsü.

EDİZDOĞAN, N. (2007). Kamu Maliyesi. Bursa: Ekin Kitabevi.

FERHATOĞLU, Emrah (2005), Bir kamu harcaması türü olarak vergi harcaması ve Türk kurumlar vergisi açısından değerlendirilmesi, Osmangazi Üniversitesi Sosyal Bilimler Dergisi, 5, 122-134.

GÜLMEZ, B. (2003). Vergi Harcaması Kavramı, Türk Vergi Sistemine Dâhil Vergi Kanunlarının Değerlendirilmesi. Hesap Uzmanları Kurulu Bilim Raporu, İstanbul.

GÖNÜL, H. Halil (2002). Vergi Harcamaları, Yaklaşım Dergisi, 111, 78-82.

HEPAKSAZ, Engin ve ÇAMURDAN, Burak (2010). Türk mali mevzuatındaki dış ticaret işlemlerine ilişkin mali yükümlülüklerin vergi harcaması uygulamaları açısından değerlendirilmesi, Finans Politik \& Ekonomik Yorumlar, 47, 542.

HORPEDAHL, J. ve PIZZOLA, B.M. (2012), A Trillion Little Subsidies: The Economic Impact of Tax Expenditures in the Federal Income Tax Code, Mercatus Center at George Mason University 24, 1-36.

MCDONALD, Hayal. (2010). Türk Vergi Sistemindeki Vergi Harcamalarının Etkinlik ve Verimlilik Açısından Değerlendirilmesi, Yayınlanmamış Doktora Tezi. Dokuz Eylül Üniversitesi, Sosyal Bilimler Enstitüsü, İzmir.

NADAROĞLU, H. (2000), Kamu Maliyesi Teorisi ( 11. Baskı). İstanbul: Beta Yayınları.

ÖZKER, A. Niyazi (2002). Vergi Hukuku ve Bütçe Politikalarında Vergi Harcaması Olgusu ve Uygulanabilir Etkinliği, eakademi/Hukuk-Ekonomi ve Siyasal Bilimler Aylık İnternet Dergisi, 7.

ÖZTÜRK, Nazım (2011), Kamu Ekonomisi, Bursa: Ekin Basım Dağıtım.

PEDÜK, Türkben (2006). Vergi Harcamaları, İstanbul: Yaklaşım Yayıncılık.

POLACKOVA, H. B., VALENDUC, M. A. C. ve SWIFT, L. Z., (2004). Tax Expenditures -Shedding Light on Government Spending through the Tax System, Lessons from Developed and Transition Economies. Washington, D.C.: The World Bank.

SARAÇ, Özgür (2010). Vergi Harcamaları ve İktisadi Etkileri, Maliye Dergisi, 159, 262-277.

SWIFT, Z. L. (2006). Managing The Effect of Tax Expenditures on National Budgets, World Bank Policy Research Working Paper .

VERGİ HARCAMALARI RAPORU (2018). Ankara: Maliye Bakanlığı. https://ms.hmb.gov.tr/uploads/2019/01/Vergi-Harcamalar_Raporu-2018.pdf

WEINBERG, Daniel H. (1987). The Distribuitonal Implications of Tax Expenditures and Comprehensive Income Taxation, National Tax Journal, 40(2), 237-253.

YILMAZ, G. Akgül (2013). Kamu Maliyesi (4. Baskı). İstanbul: Türkmen Kitapevi. 